\title{
Social Identity of Offshore Employees: When Do Organizational Identity and Identification Improve International Business Performance?-An Abstract
}

\author{
Gen Fukutomi, Kenichiro Kuroiwa, and Keiko Kotani
}

\begin{abstract}
For businesses operating globally, employees may be located overseas, which can affect their social identity, performance, and identification with their organization and assigned market. According to the current literature, when offshore employees view their organization as being especially valuable, they may lack connectedness with the assigned market. In particular, when employees have strong organizational identification with the home headquarters, they may fail to cultivate an understanding of the local market. However, it cannot be assumed that a linear relationship exists between organizational identity and international business performance.

Our goal is to identify conditions under which a high level of organizational identity and identification improves or harms business performance. For this purpose, we conducted a survey of 657 offshore employees who were currently or who had previously been posted overseas for more than 1 year. According to our quantitative study, a higher level of organizational identification with the local unit lowers performance when employees indicate weaker organizational identity overall. Nonetheless, a higher level of organizational identity itself improves international business performance.
\end{abstract}

References available upon request.

\footnotetext{
G. Fukutomi $(\bowtie)$

Kyoto Sangyo University, Kyoto, Japan

e-mail: genf@cc.kyoto-su.ac.jp

K. Kuroiwa $\bullet$ K. Kotani

Aoyama Gakuin University, Tokyo, Japan

e-mail: kuroiwa@gsim.aoyama.ac.jp; k.kotani@w4.dion.ne.jp 